\title{
Diagnostic accuracy of point-of-care testing for acute coronary syndromes, heart failure and thromboembolic events in primary care: a cluster-randomised controlled trial
}

\author{
Yuki Tomonaga', Felix Gutzwiller ${ }^{1}$, Thomas F Lüscher ${ }^{2}$, Walter F Riesen ${ }^{3}$, Markus Hug ${ }^{4}$, Albert Diemand ${ }^{5}$, \\ Matthias Schwenkglenks', Thomas D Szucs ${ }^{6^{*}}$
}

\begin{abstract}
Background: Evidence of the clinical benefit of 3-in-1 point-of-care testing (POCT) for cardiac troponin T (cTnT), $\mathrm{N}$-terminal pro-brain natriuretic peptide (NT-proBNP) and D-dimer in cardiovascular risk stratification at primary care level for diagnosing acute coronary syndromes (ACS), heart failure (HF) and thromboembolic events (TE) is very limited. The aim of this study is to analyse the diagnostic accuracy of POCT in primary care.

Methods: Prospective multicentre controlled trial cluster-randomised to POCT-assisted diagnosis and conventional diagnosis (controls). Men and women presenting in 68 primary care practices in Zurich County (Switzerland) with chest pain or symptoms of dyspnoea or TE were consecutively included after baseline consultation and working diagnosis. A follow-up visit including confirmed diagnosis was performed to determine the accuracy of the working diagnosis, and comparison of working diagnosis accuracy between the two groups.
\end{abstract}

Results: The 218 POCT patients and 151 conventional diagnosis controls were mostly similar in characteristics, symptoms and pre-existing diagnoses, but differed in working diagnosis frequencies. However, the follow-up visit showed no statistical intergroup difference in confirmed diagnosis frequencies. Working diagnoses overall were significantly more correct in the POCT group ( $75.7 \%$ vs $59.6 \%, p=0.002)$, as were the working diagnoses of ACS/HF/TE (69.8\% vs 45.2\%, $\mathrm{p}=0.002)$. All three biomarker tests showed good sensitivity and specificity.

Conclusion: POCT confers substantial benefit in primary care by correctly diagnosing significantly more patients.

Trial registration: DRKS: DRKS00000709

\section{Background}

Chest pain, tightness, pressure or squeezing, along with dyspnoea and heartburn-like sensations, are a diagnostic challenge in primary care medicine. Symptoms are often an inadequate guide to a working diagnosis. Common causes of chest pain and dyspnoea include stable angina, gastrointestinal disease, panic disorder, viral infection and musculoskeletal pain, but the most serious suspects include acute coronary syndromes (ACS), heart failure (HF) and thromboembolic events (TE) [1-3].

\footnotetext{
*Correspondence: thomas.szucs@unibas.ch

${ }^{6}$ European Center of Pharmaceutical Medicine, University of Basel, 4051

Basel, Switzerland

Full list of author information is available at the end of the article
}

Numerous cardiovascular biomarkers are now available [4]. Cardiac troponin $\mathrm{T}$ (cTnT), N-terminal probrain natriuretic peptide (NT-proBNP) and D-dimer are the most used, in particular for cardiovascular risk stratification [5]. New multifunctional devices measure all three in minutes.

cTnT is a highly specific and sensitive protein for diagnosing myocardial necrosis: elevation diagnoses ACS and identifies patients at high risk of cardiac events [6]. NT-proBNP differentiates cardiac from non-cardiac causes of dyspnoea and excludes HF in symptomatic patients [7]. As reported by Jernberg et al. [8], NTproBNP analysis improves the early detection of patients with potential ACS and non ST-segment elevation

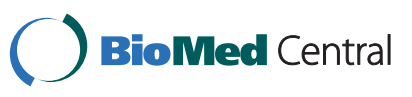


myocardial infarction (NSTEMI). NT-proBNP elevation also has high prognostic value, being associated with increased mortality in cardiovascular patients [9]. The strength of D-dimer, an indicator of fibrin degradation and coagulation activation, lies in its high negative predictive value (NPV) for excluding TE (deep vein thrombosis [DVT] and pulmonary embolism [PE]) [10]. Its specificity is usually low since increased levels are encountered in many non-thrombotic situations [11].

Our aim was to analyse the benefit of POCT for cardiovascular risk stratification in primary care. We hypothesised that POCT testing for cTnT, NT-proBNP, and/or D-dimer in venous whole blood would allow for a more accurate diagnosis of ACS, HF and TE by officebased, Swiss general practitioners.

\section{Methods}

\section{Patients and study design}

We randomised 68 primary care practices in Zurich County (Switzerland) to diagnostic aid from a POCT analyser ( $\mathrm{n}=33$ [39 physicians]; POCT group) or to conventional diagnosis employing best clinical practice ( $\mathrm{n}=35$ [40 physicians]; controls). We randomised only practices at least $8-10 \mathrm{~km}$ from Zurich and Winterthur where laboratories with specialised diagnostic systems are less available.

All patients presenting with potentially cardiovascular chest pain or symptoms between May 2006 and August 2007 were invited to participate. Patients gave written informed consent and the study received approval from the cantonal ethics committee (Kantonale Ethikkommission Zürich), in line with the Declaration of Helsinki (1996) and Good Clinical Practice guidelines. Non-inclusion criteria were refusal of consent, presentation $>5$ days after symptom onset, recent anticoagulant treatment, severe renal dysfunction and cancer therapy. Rationales for the exclusion criteria were the normalisation of the cTnT level five days after ACS, the fact that cTnT may be increased even in the absence of clinically suspected acute myocardial ischemia in patients with renal insufficiency, and the unpredictable effect of anticoagulant treatment and cancer therapy on the biomarkers' concentration $[12,13]$.

Physicians examined all patients before making a working diagnosis of ACS, HF, TE, musculoskeletal or "other" (specified) problems based on the patients characteristics, medical history, symptoms, physical findings and, in the POCT group, the biomarkers (it was not mandatory to analyse all biomarkers: the physicians had the possibility to choose if and which biomarker test was necessary). At follow-up 3 weeks later the same physician reviewed the working diagnosis. The follow-up diagnosis was defined as the confirmed diagnosis. Follow-up data of patients requiring additional specialist visits or hospitalisation were provided by specialist or hospital reports.

\section{Technical information}

POCT practices received a bedside Cardiac Reader ${ }^{\circledR}$ (Roche Diagnostics, Switzerland), a 3-in-1 device that determines cTnT, NT-proBNP or D-dimer in heparinised venous whole blood within 8-12 min. Measurement was quantitative for each parameter over the ranges 0.05 $2.00 \mathrm{ng} / \mathrm{ml}, 60-3000 \mathrm{pg} / \mathrm{ml}$ and $0.1-4.0 \mu \mathrm{g} / \mathrm{ml}$, with validated positive/negative cut-offs of $0.1 \mathrm{ng} / \mathrm{ml}, 125 \mathrm{pg} / \mathrm{ml}$ and $0.5 \mu \mathrm{g} / \mathrm{ml}$. Instruction to the POC-instrument always was performed by the same specialist from Roche Diagnostic. All GPs who received a POCT device received advice on the interpretation of test results. Test quality was monitored using the internal and external quality controls required by Swiss federal law and the Swiss Commission for Quality Assurance in the Medical Laboratory (QUALAB) [14].

\section{Statistical analysis}

Data were analysed using SPSS 14.0 for Windows. Intergroup comparisons of categorical data were performed using univariate logistic regression; standard errors and $\mathrm{p}$ values were adjusted for the effect of clustering utilising a generalised estimating equations approach. We detected an interclass correlation coefficient of 0.073 for the main binary endpoint of a correct versus incorrect working diagnosis.

To evaluate diagnostic test quality and performance we plotted receiver operating characteristic (ROC) curves, defined as plots of test sensitivity on the $y$ axis vs. 1-specificity on the $x$ axis. The area under the ROC curve (AUC) combining sensitivity and specificity was used to measure overall diagnostic test performance and was interpreted as the average sensitivity value for all possible specificity values.

\section{Results}

\section{Study population}

Of the 369 patients recruited, 218 (59\%) were enrolled in the POCT group (7 \pm 10 /practice) and 151 (41\%) in the control group ( $4 \pm 4$ /practice). Characteristics and blood parameters were similar in both groups (Table 1).

The interval between symptom onset and baseline visit was much longer in the POCT group because some (mainly POCT) patients presented over 5 days after symptom onset (non-inclusion criterion). We contacted the practices for specific explanations. In almost all cases the patients had visited the physician in the previous weeks/months ( $>>5$ days) with similar problems. Due to new or exacerbated symptoms (onsetting in the previous 5 days) they revisited their physician who reported the date of their first or previous visit incorrectly. After 
Table 1 Baseline demographics, clinical chemistry and interval between symptom onset and baseline presentation

\begin{tabular}{|c|c|c|}
\hline Variable & $\begin{array}{c}\text { POCT } \\
(n=218) \\
n(\%) \\
\text { or mean } \pm \text { SD }\end{array}$ & $\begin{array}{c}\text { Controls }(n=151) \\
n(\%) \\
\text { or mean } \pm \text { SD }\end{array}$ \\
\hline Men & $121(57.9)$ & $83(58.0)$ \\
\hline Age [years] & $65 \pm 16$ & $64 \pm 17$ \\
\hline Weight $[\mathrm{kg}]$ & $80 \pm 17$ & $78 \pm 17$ \\
\hline Height & $169 \pm 10$ & $169 \pm 9$ \\
\hline Body mass index $\left[\mathrm{kg} / \mathrm{m}^{2}\right]$ & $28 \pm 5$ & $27 \pm 6$ \\
\hline Glucose $[\mathrm{mmol} / \mathrm{l}]$ & $5.9 \pm 1.5$ & $6.3 \pm 2.1$ \\
\hline Creatinine $[\mathrm{mmol} / \mathrm{l}]$ & $84.4 \pm 29.1$ & $84.4 \pm 22.4$ \\
\hline High-density lipoprotein [mmol/l] & $1.4 \pm 0.7$ & $1.4 \pm 0.5$ \\
\hline Low-density lipoprotein $[\mathrm{mmol} / \mathrm{l}]$ & $2.9 \pm 1.0$ & $3.3 \pm 1.0$ \\
\hline Triglycerides $[\mathrm{mmol} / \mathrm{l}]$ & $1.7 \pm 1.1$ & $1.7 \pm 1.0$ \\
\hline Interval between symptom onset and baseline visit [all patients, days] & $3.3 \pm 9.8$ & $1.7 \pm 1.7$ \\
\hline Interval between symptom onset and baseline visit [patients presenting $<5$ days after symptom onset, days] & $\begin{array}{l}1.2 \pm 1.4 \\
(n=185)\end{array}$ & $\begin{array}{l}1.5 \pm 1.4 \\
(n=141)\end{array}$ \\
\hline
\end{tabular}

POCT, point-of-care testing; SD, standard deviation.

patients with incorrect symptom onset were excluded, the average interval between symptom onset and baseline visit became similar in the two groups.

\section{Presenting symptoms}

Many patients reported mixed sensations of pain or discomfort. Both groups had high prevalence of acute chest pain, tightness, pressure or squeezing, dyspnoea and heartburn-like sensations. Other symptoms were relatively rare (Table 2 ). The groups statistically differed in rates of acute chest and calf pain.

\section{Medical history}

The most frequent pre-existing diagnoses were hypertension, diabetes and angina. Only the proportion of patients with previously diagnosed HF differed substantially between the groups (Table 3). Pathological electrocardiograms (ECGs) were more prevalent in controls.

Table 2 Presenting symptoms

\begin{tabular}{lcc}
\hline Symptoms & $\begin{array}{c}\text { POCT }(\mathbf{n}=\mathbf{2 1 8}) \\
\mathbf{n}(\%)\end{array}$ & $\begin{array}{c}\text { Controls }(\mathbf{n}=\mathbf{1 5 1}) \\
\mathbf{n}(\%)\end{array}$ \\
\hline Acute chest pain & $99(45)$ & $96(64)$ \\
Tightness, pressure, or & $138(63)$ & $92(61)$ \\
squeezing in the chest & $99(45)$ & $69(46)$ \\
Dyspnoea & $32(15)$ & $19(13)$ \\
Heartburn-like sensation & $16(7)$ & $5(3)$ \\
Heaviness and tension & & \\
sensations in the leg & $16(7)$ & $4(3)$ \\
Calf pain & $4(2)$ & $4(3)$ \\
Neck vein congestion & $22(10)$ & $9(6)$ \\
Oedema & $7(3)$ & $4(3)$ \\
Nocturia & $2(1)$ & $3(2)$ \\
Cyanosis & &
\end{tabular}

Reasons for hospitalisation in the previous 12 months were diverse and only partially cardiovascular.

\section{Working and confirmed diagnoses}

Some working diagnoses differed in frequency between the groups (Figure 1). In the POCT group ACS was less frequent, and HF more frequent, than in controls $(\mathrm{p}=$ 0.03 and $p=0.04)$. TE was similar in frequency $(\mathrm{p}=$ $0.81)$, as were musculoskeletal problems $(\mathrm{p}=0.34)$ and "other" diagnoses (e.g. stable angina, pleuritis, psychiatric problems, viral infection; $\mathrm{p}=0.97$ ).

However, confirmed diagnoses did not differ in frequency (Figure 2). Intergroup ACS and TE were similar

Table 3 Medical history

\begin{tabular}{lcc}
\hline & $\begin{array}{c}\text { POCT ( } \mathbf{n}=\mathbf{2 1 8}) \\
\mathbf{n ~ ( \% )}\end{array}$ & $\begin{array}{c}\text { Controls ( }=\mathbf{1 5 1}) \\
\mathbf{n}(\%)\end{array}$ \\
\hline Malignant tumour & $15(7)$ & $7(5)$ \\
Thrombosis/embolism & $12(6)$ & $13(9)$ \\
Myocardial infarction & $15(7)$ & $11(7)$ \\
Heart failure & $19(9)$ & $5(3)$ \\
Angina & $20(9)$ & $15(10)$ \\
Renal failure & $13(6)$ & $8(5)$ \\
Diabetes & $34(16)$ & $15(10)$ \\
Aneurysm/dissection & $1(1)$ & $23(15)$ \\
Hypertension & $48(22)$ & $5(3)$ \\
Chronic obstructive & $9(4)$ & $5(3)$ \\
pulmonary disease & $10(5)$ & $24(16)$ \\
Peripheral arterial disease & $35(16)$ & $59(39)$ \\
Smokers & $71(33)$ & $25(17)$ \\
Pathological & & \\
electrocardiogram & $43(20)$ & \\
Hospitalisation in previous 12 & & \\
months & & \\
\hline
\end{tabular}




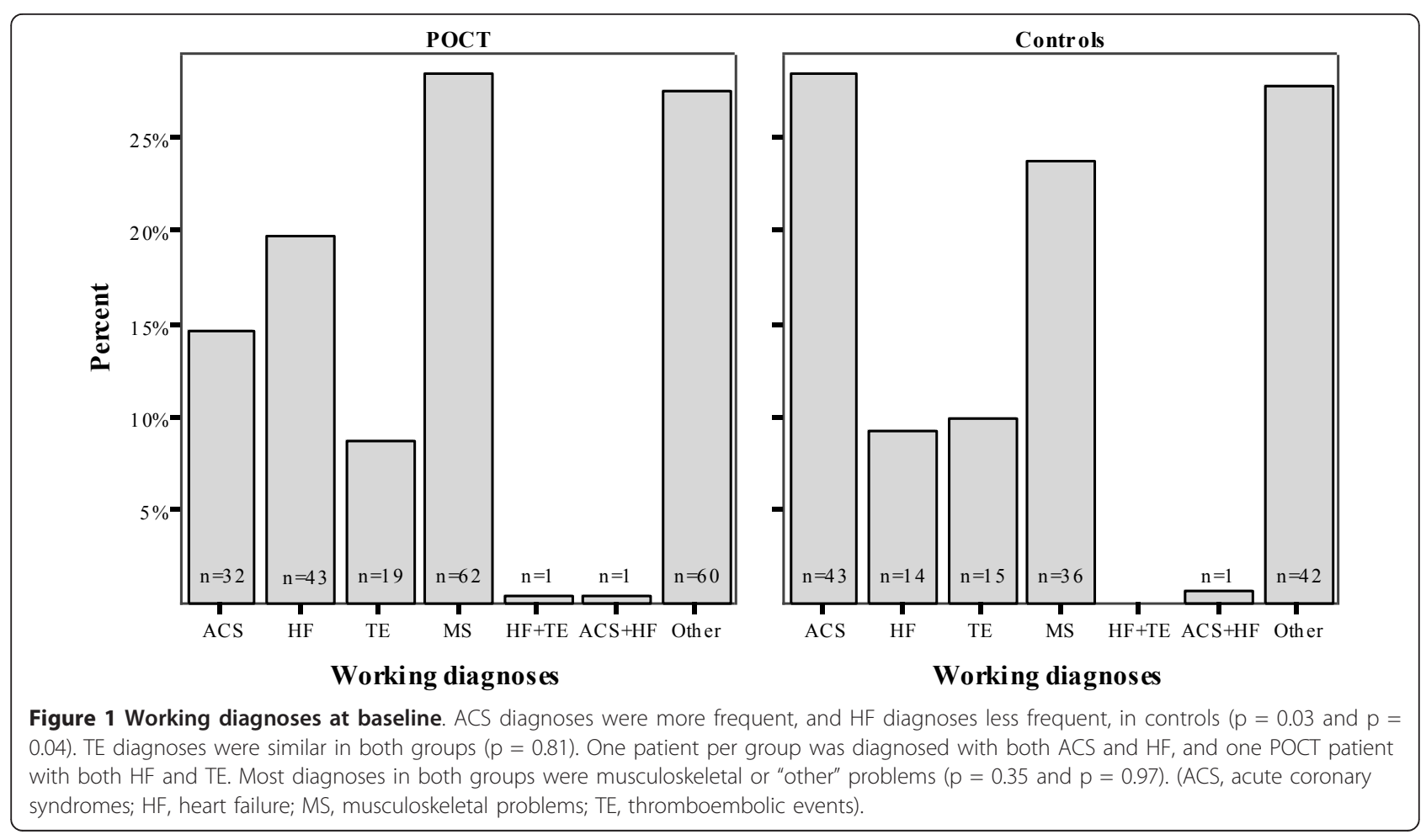

( $\mathrm{p}=0.87$ and $\mathrm{p}=0.93$ ), while HF remained substantially, but non-significantly, more frequent in the POCT group ( $p=0.08$ ). In both groups, two-thirds of patients had musculoskeletal problems $(\mathrm{p}=0.49)$ or "other" diagnoses $(p=0.57)$.

\section{Diagnostic accuracy of the working diagnosis}

In the POCT group 165/218 working diagnoses (76\%) proved correct vs $90 / 151(60 \%)$ in controls ( $p=0.002)$. Seventy percent of the working diagnoses of ACS, HF and TE proved correct in the POCT group vs $45 \%$ in

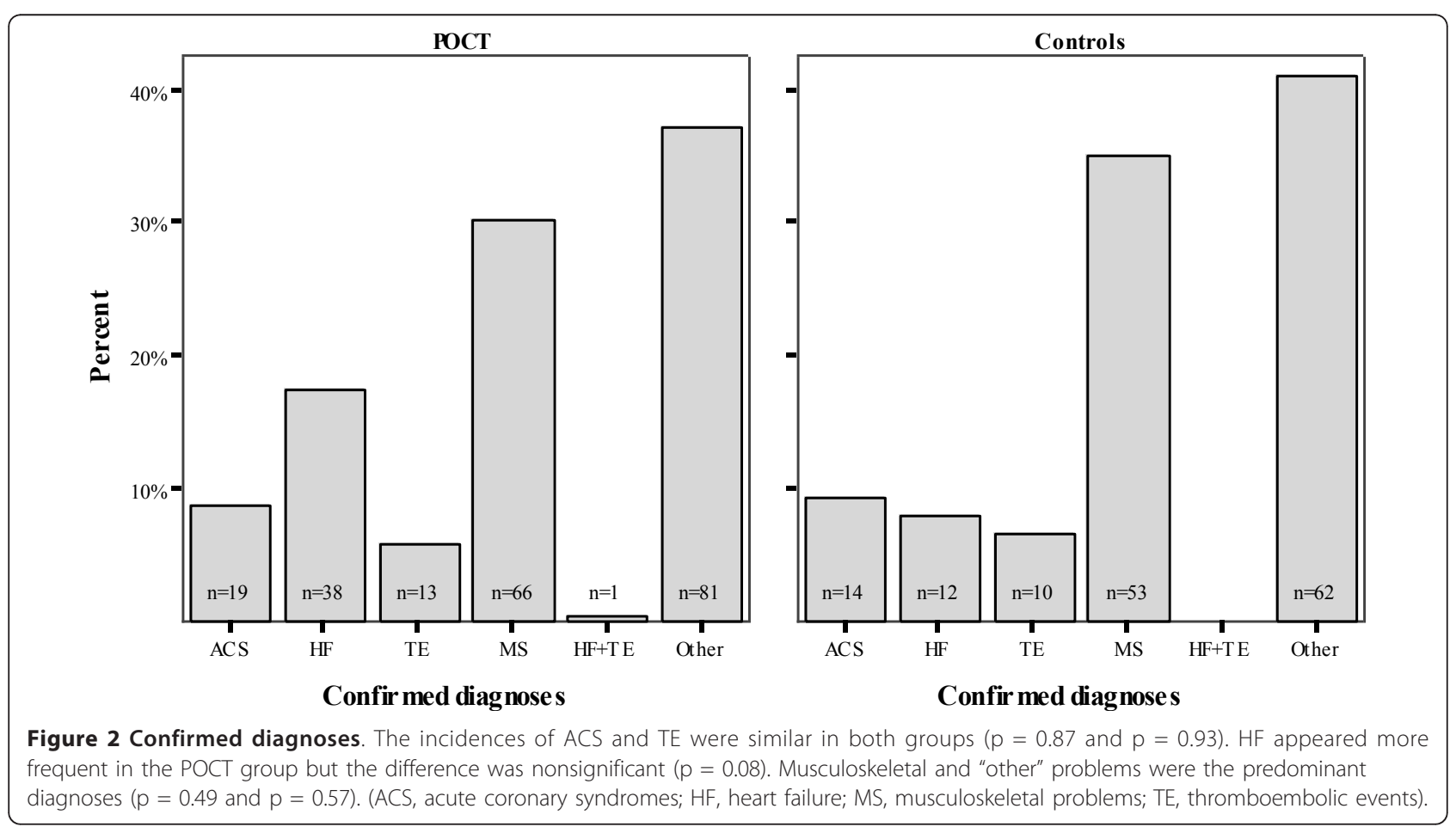


the controls $(\mathrm{p}=0.002)$, with false-positives in $29(30 \%)$ patients vs $40(55 \%)$ patients, respectively. In contrast, correctness of the remaining working diagnoses (musculoskeletal or "other" problems) did not differ: $80 \%$ in the POCT group vs $73 \%$ in the controls ( $\mathrm{p}=0.31$ ).

Except for ACS, where sensitivity was higher in controls, working diagnoses were more sensitive in the POCT group (Table 4). However, specificity was similar in both groups, except for ACS, where it was higher in the POCT group. NPVs of the ACS, HF, and TE diagnoses were near-identical. Overall these results confirmed greater diagnostic accuracy in the POCT group.

\section{Biomarker performance in the POCT group}

Individual test sensitivities and NPVs were generally higher when assessed using the confirmed diagnoses. Specificities, in contrast, differed only marginally.

The diagnostic power of the cTnT test was higher when assessed using the confirmed diagnoses: sensitivity and NPV were $17 \%$ and $6 \%$ higher (Table 5). Seven patients had a false-negative result and risked a wrong diagnosis. Two had a history of myocardial infarction and were polymedicated (statins, aspirin, diuretics, $\beta$-blockers); based on their history and medication they were correctly diagnosed with ACS. Another had a history of angina and was polymedicated: recurrent angina was suspected. A patient presenting 5 hours after symptom onset was diagnosed with stable angina. The final three patients were diagnosed correctly from their symptoms.

The diagnostic power of the NT-proBNP tests was high: all patients with HF also had a positive NT-proBNP, and while none of those with a negative NT-proBNP had HF. Specificity was $72 \%$.

The D-dimer test had a sensitivity of $93 \%$, specificity of $78 \%$ and NPV of $99 \%$. The single false-negative was in a 65 -year-old man with a history of cancer who was

Table 4 Diagnostic accuracy of the working diagnoses sensitivity, specificity and NPV

\begin{tabular}{llcccccc}
\hline & & \multicolumn{2}{c}{ Sensitivity } & \multicolumn{2}{c}{ Specificity } & \multicolumn{2}{c}{ NPV } \\
\hline \multirow{2}{*}{ ACS } & & $\mathbf{n}$ & $\%$ & $\mathbf{n}$ & $\%$ & $\mathbf{n}$ & $\%$ \\
& POCT & $17 / 19$ & 90 & $183 / 199$ & 92 & $183 / 185$ & 99 \\
& Controls & $14 / 14$ & 100 & $107 / 137$ & 78 & $107 / 107$ & 100 \\
\hline HF & POCT & $39 / 39$ & 100 & $173 / 179$ & 97 & $173 / 173$ & 100 \\
& Controls & $10 / 12$ & 83 & $134 / 139$ & 96 & $134 / 136$ & 99 \\
\hline TE & POCT & $14 / 14$ & 100 & $198 / 204$ & 97 & $198 / 198$ & 100 \\
& Controls & $9 / 10$ & 90 & $135 / 141$ & 96 & $135 / 136$ & 99 \\
\hline MS & POCT & $54 / 66$ & 82 & $144 / 152$ & 95 & $144 / 156$ & 92 \\
& Controls & $34 / 53$ & 64 & $96 / 98$ & 98 & $96 / 115$ & 84 \\
\hline Other & POCT & $55 / 81$ & 68 & $132 / 137$ & 96 & $132 / 158$ & 84 \\
& Controls & $37 / 62$ & 60 & $84 / 89$ & 94 & $84 / 109$ & 77 \\
\hline
\end{tabular}

(i) ACS, acute coronary syndromes; HF, heart failure; MS, musculoskeletal problems; NPV, negative predictive value; TE, thromboembolic events. correctly diagnosed with deep vein thrombosis from his symptoms.

The cTnT ROC curve based on the confirmed diagnoses was somewhat oddly shaped because physicians often recorded the result simply as positive or negative $(<0.1 \mathrm{ng} / \mathrm{ml})$. In such cases positive and negative cTnT values were arbitrarily entered as $0.1 \mathrm{ng} / \mathrm{ml}$ and $0.0 \mathrm{ng} /$ $\mathrm{ml}$. Very high test specificity accounted for the measured AUC, 82\% (Figure 3). The NT-proBNP and Ddimer ROC curves were more regular, achieving high sensitivity and specificity, with AUCs of $94 \%$ and $93 \%$.

\section{Discussion}

Our results emphasise the clinical value of POCT using a novel cardiovascular marker device measuring cTnT, NT-proBNP and D-dimer for the risk stratification of ACS, HF and TE in primary care. Diagnoses were more accurate in the POCT group. In particular, POCTassisted physicians avoided numerous false-positive ACS, HF, and TE diagnoses. This evidence supports the use of cTnT, NT-proBNP and D-dimer in diagnosing patients with chest pain or other potentially cardiovascular symptoms. Analysis of these biomarkers provides clinical benefit by more accurately ruling in/out ACS, HF and TE, each with significant management implications.

\section{ACS diagnosis}

In previous studies, atypical or absent chest pain has been associated with failure to recognise ACS by either physician or patient in up to one third of cases [15]. Our study shows a reverse tendency: the number of working diagnoses of ACS was unexpectedly high, in particular in controls. Perhaps the study topic alerted physicians to ACS as a possible cause of chest pain, causing them to overestimate its incidence, in particular in the unassisted control group. Many working diagnoses were overturned on follow-up, resulting in very high sensitivity and low specificity. In contrast, the POCT group suspected fewer ACS, resulting in high sensitivity and specificity. Despite two false-negatives in patients wrongly suspected of having stable angina, POCT was more accurate in stratification: ACS was correctly ruled in/out in $92 \%$ of POCT patients vs $78 \%$ of controls.

Overall, these findings support the notion that when combined with clinical symptoms and ECG screening, troponin assay improves diagnostic accuracy, in line with American College of Cardiology/American Heart Association guidelines on managing patients with unstable angina or NSTEMI [16]. Except for the sensitivity results discussed above, our data reflect the $94 \%$ sensitivity and $97 \%$ NPV of the cTnT test for ACS reported by Lüscher et al. [17] in 92 patients with chest pain, and the $100 \%$ sensitivity, $42 \%$ specificity and $100 \%$ 
Table 5 Sensitivity, specificity and NPV of cardiovascular biomarkers in relation to the working and confirmed diagnoses

\begin{tabular}{|c|c|c|c|c|c|c|c|}
\hline \multirow[t]{2}{*}{ Biomarker } & \multirow[t]{2}{*}{ Working/Confirmed diagnosis } & \multicolumn{2}{|c|}{ Sensitivity } & \multicolumn{2}{|c|}{ Specificity } & \multicolumn{2}{|c|}{ NPV } \\
\hline & & $\mathrm{n}$ & $\%$ & $\mathrm{n}$ & $\%$ & $\mathrm{n}$ & $\%$ \\
\hline \multirow[t]{2}{*}{$\overline{c T n T}$} & Working ACS & $11 / 26$ & 42 & $113 / 121$ & 93 & $113 / 128$ & 88 \\
\hline & Confirmed ACS & $10 / 17$ & 59 & $121 / 130$ & 93 & $121 / 128$ & 95 \\
\hline \multirow[t]{2}{*}{ NT-proBNP } & Working HF & $33 / 35$ & 94 & $26 / 35$ & 74 & $26 / 28$ & 93 \\
\hline & Confirmed HF & $31 / 31$ & 100 & 28/39 & 72 & $28 / 28$ & 100 \\
\hline \multirow[t]{2}{*}{ D-dimer } & Working TE & $16 / 20$ & 80 & $78 / 98$ & 80 & $78 / 82$ & 95 \\
\hline & Confirmed TE & $13 / 14$ & 93 & $81 / 104$ & 78 & $81 / 82$ & 99 \\
\hline
\end{tabular}

(i) ACS, acute coronary syndromes; cTnT, cardiac troponin T; HF, heart failure; NPV, negative predictive value; NT-proBNP, N-terminal pro-brain natriuretic peptide; $\mathrm{TE}$, thromboembolic events.

NPV reported by Fehr et al. [18] in a cross-sectional study of asymptomatic haemodialysis patients. In our study, the high AUC value of the cTnT ROC curve, a measure of overall quality, was largely due to the very high test specificity. To rule out ACS on the basis of cTnT, a minimum of 5 hours (time to increase above the reference range) and a maximum of 5-7 days (time for biomarker level normalisation) must normally elapse after symptom onset. Table 1 confirms that most patients complied with these time limits.

The cTnT assay itself yielded seven false-negatives. Most patients concerned (5/7) were correctly diagnosed from their history and symptoms. Recurrent angina was suspected in the other two patients. High drug consumption in three patients, and the short interval (5 h) between symptom onset and presentation in one patient, may partially explain the false-negatives. Misuse of the POCT device may account for the other cases. That the same practice made 4/7 false-negative diagnoses supports this explanation, highlighting the importance of adequate training on POCT devices. In our study, training on the POCT instrument always was performed by the same Roche Diagnostics specialist, but some staff members were instructed by their colleagues only.

\section{HF diagnosis}

HF is a common and increasing public health problem [19]. Diagnosis in the primary care setting can be difficult and incorrect in up to $70 \%$ of cases [20]. Echocardiography is the gold standard for identifying and confirming left ventricular systolic dysfunction [21] but is relatively expensive and generally beyond the resources of general practitioners [22,23]. Even where available, its appropriate use requires extensive training and experience.

In our study, diagnosis of HF in the POCT group showed high sensitivity, specificity and NPV. Sensitivity in the controls was relatively low, but both specificity and NPV were high. These results indicate that HF was better identified in the POCT group, presumably because of the NT-proBNP data. Assay sensitivity and NPV were perfect: all patients with HF had elevated NT-proBNP values, whereas HF was correctly excluded in all patients with normal values. The very high AUC of the NTproBNP ROC curve (Figure 3 ) reflects the test's high diagnostic accuracy. These results confirm earlier studies: the NZ prospective Natriuretic Peptides in the Community Study, a randomised controlled trial of the effect of NT-proBNP on HF diagnostic accuracy in primary care,

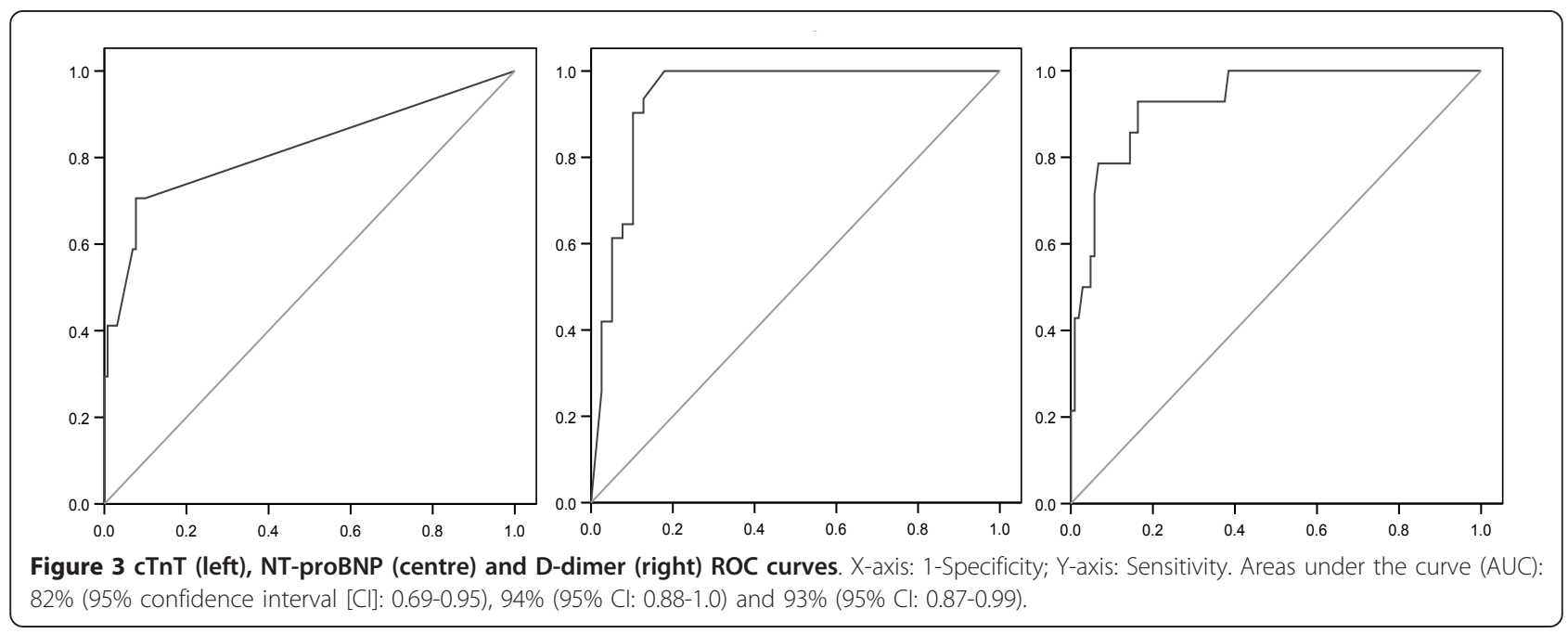


showing significant improvement in the BNP group over controls [24]; a UK study in 306 primary care referrals for suspected HF emphasising the high NPV of the NT-proBNP assay (ECG had no additional predictive value) [25]; and the prospective 600-patient $N$-terminal PRo-BNP Investigation of Dyspnea in the Emergency department (PRIDE) study which found the test with its 99\% NPV to be a valuable addition to standard clinical assessment for identifying and excluding acute HF: a positive NT-proBNP was the strongest independent predictor of a final positive diagnosis of HF.

\section{TE diagnosis}

TE includes PE and DVT, which are closely interrelated since $90 \%$ of symptomatic PE arise from leg vein thrombi [26]. It's well recognised that TE cannot unequivocally be diagnosed from the history and physical examination alone, even in high-risk patients [27]. The recent development of non-invasive $\mathrm{D}$-dimer blood tests with a very high NPV has markedly enhanced the accuracy of diagnosis [28].

In our study, the sensitivity, specificity and NPV of the TE diagnoses were good in both groups, making it difficult to determine whether diagnoses in the POCT group were more accurate. The D-dimer assay showed moderate specificity but very high sensitivity and NPV. The only patient with a false-negative $\mathrm{D}$-dimer was a 65 -yearold man with a history of cancer who was correctly diagnosed with a DVT based on his symptoms. The NPV confirmed the assay's power in excluding TE. While a negative D-dimer safely excludes TE, patients with a positive result should still be screened for PE and DVT, in particular in the presence of typical symptoms. Our results are consistent with those of other studies, e.g. Leclercq et al. or Schutgens et al. [29,30].

\section{Study limitations and future research}

Some limitations of the study require discussion. For example, we confined ourselves to Zurich County for practical reasons; whether the results can or cannot be extrapolated to less urbanised areas remains to be determined.

A second limitation was patient recruitment. Initially, recruitment was clearly higher in the POC group. We put this down to a difference in study awareness: the device on their premises made POCT physicians more study-aware. Control physicians, on the other hand, had only the study protocol and the questionnaires to remind them, and perhaps forgot to recruit; after we initiated regular telephone reminders, recruitment rates became almost equal in both groups.

The follow-up diagnoses were another limitation. In principle, they should have been performed by independent blinded assessors but this was not feasible. For practical and data protection reasons, they were made by the same physician who was primarily consulted by the patient. We are aware of the potential for bias, e.g. due to possible underreporting of incorrect baseline diagnoses leading to a false high rate of correct baseline diagnoses or a false low difference between study arms. On the other hand, for patients referred for further diagnostic work-up (including all patients at potentially high cardiovascular risk), GPs received a written report on the second-stage assessment as well as information on further clinical management, which substantially reduced the risk of bias.

A fourth limitation concerns possible underestimation of the number of HF diagnoses in the controls. Not only were there significantly more pre-existing HF diagnoses in the POCT group, but the total number of newly identified HF patients was also greater. We assume that the POCT physicians used the NT-proBNP value as diagnostic criterion to identify more patients with NYHA class I-II HF. Indeed, early stages of HF are often asymptomatic and difficult to identify without accurate screening. Some patients with mild HF may not have been diagnosed as a result, and this tendency would have been stronger in the controls.

As shown in Table 5 which compares biomarker performance in the POCT group to the working and confirmed diagnoses, it seems that in some cases the GP decided to ignore the results of the biomarker tests. It is unknown if there was a lack of confidence in the biomarkers, if there was a problem with the interpretation of the results, or if GPs gave more importance to physical findings, symptoms, and patient history. In any case, this finding emphasises the importance of training and continuing medical education.

Health-economic and cost-effectiveness studies of cardiovascular risk stratification using POCT are rare. Some studies have analysed the costs and benefits of a single biomarker for a defined disease. Thus Nielsen et al. [31] concluded that NT-proBNP testing in primary care patients with dyspnoea halved the need for echocardiographic screening. Gustafsson et al. [32] reported that a normal NT-proBNP effectively ruled out left ventricular systolic dysfunction in primary care patients referred for echocardiography, thereby avoiding unnecessary further investigation. Siebert et al. [33] found that NT-proBNP measurement improved patient outcome, reduced echocardiography use by $58 \%$, prevented $13 \%$ of hospitalisations and reduced hospital stay by $12 \%$. Similar studies have been performed for other biomarkers, but a more general evaluation is needed of the possible benefits of POCT for ACS, HF and TE in primary care. 


\section{Conclusions}

This study found substantial benefit for POCT diagnosis in cardiovascular risk stratification at the primary care level. Non-invasive analysis of cTnT, NT-proBNP and D-dimer produced more accurate diagnoses of ACS, HF and TE in the POCT group. Given the potential for substantial health-economic savings, we plan a fuller investigation based on the clinical outcomes of this study.

\section{Acknowledgements}

We would like to thank the recruiting physicians and all patients for their cooperation. We also appreciated the contributions of Claudia Brüngger from the University of Basel for her support with physician recruitment and instruction, and of Matthias Bramkamp from the University Hospital of Zurich for his critical revision of the manuscript.

This work was supported by Roche Diagnostics (Switzerland), who provided the POCT instruments, reagents, and an unrestricted educational grant. Presentations: the study results were presented at the $15^{\text {th }}$ Wonca Europe Conference 2009 in Basel (Switzerland) which was held together with the $32^{\text {nd }}$ national Swiss Society of General Medicine SSMG/SGAM congress (1619 September 2009).

\section{Author details}

${ }^{1}$ Institute of Social and Preventive Medicine, University of Zurich, 8001 Zurich, Switzerland. ${ }^{2}$ Department of Cardiology, Cardiovascular Center, University Hospital Zurich, 8091 Zurich, Switzerland. ${ }^{3}$ Institute for Clinical Chemistry and Haematology, Kantonsspital, 9007 St. Gallen, Switzerland. ${ }^{4}$ FMH Foederatio Medicorum Helveticorum (Swiss Medical Association), 2800 Delémont, Switzerland. ${ }^{5}$ Roche Diagnostics (Schweiz) AG, 6343 Rotkreuz, Switzerland. ${ }^{6}$ European Center of Pharmaceutical Medicine, University of Basel, 4051 Basel, Switzerland.

\section{Authors' contributions}

All authors contributed to the conception and design; YT undertook the statistical analysis and MS advised on the analysis of clustered-randomised data; all authors contributed to the interpretation of data and have been involved in the drafting of the manuscript or revising it critically for important intellectual content; and have given final approval of the version to be published.

\section{Competing interests}

Prof. Felix Gutzwiller and Albert Diemand own some Hoffmann-La Roche stock. Albert Diemand declares a financial conflict, since Roche Diagnostics (Switzerland) provided all POCT instruments, reagents, and an unrestricted educational grant. However, he had no access to the dataset and no influence on the data analysis performed at the Institute of Social and Preventive Medicine, Zurich University. All other authors have no conflicts of interest.

Received: 26 April 2010 Accepted: 24 March 2011

Published: 24 March 2011

\section{References}

1. Brieger D, Eagle KA, Goodman SG, Steg PG, Budaj A, White K, Montalescot G: Acute coronary syndromes without chest pain, an underdiagnosed and undertreated high-risk group: insights from the Global Registry of Acute Coronary Events. Chest 2004, 126(2):461-9.

2. Punukollu H, Khan IA, Punukollu G, Gowda RM, Mendoza C, Sacchi TJ: Acute pulmonary embolism in elderly: clinical characteristics and outcome. International journal of cardiology 2005, 99(2):213-6.

3. Godfrey C, Harrison MB, Medves J, Tranmer JE: The symptom of pain with heart failure: a systematic review. Journal of cardiac failure 2006, 12(4):307-13.

4. Jaffe AS, Babuin L, Apple FS: Biomarkers in acute cardiac disease: the present and the future. Journal of the American College of Cardiology 2006, 48(1):1-11.
5. Harrison A, Amundson S: Evaluation and management of the acutely dyspneic patient: the role of biomarkers. The American journal of emergency medicine 2005, 23(3):371-8.

6. Newby LK, Christenson RH, Ohman EM, Armstrong PW, Thompson TD, Lee KL, Hamm CW, Katus HA, Cianciolo C, Granger CB, Topol EJ, Califf RM: Value of serial troponin $\mathrm{T}$ measures for early and late risk stratification in patients with acute coronary syndromes. The GUSTO-Ila Investigators. Circulation 1998, 98(18):1853-9.

7. Januzzi JL, van Kimmenade R, Lainchbury J, Bayes-Genis A, Ordonez-Llanos J, Santalo-Bel M, Pinto YM, Richards M: NT-proBNP testing for diagnosis and short-term prognosis in acute destabilized heart failure: an international pooled analysis of 1256 patients: the International Collaborative of NTproBNP Study. European heart journal 2006, 27(3):330-7.

8. Jernberg $T$, Stridsberg $M$, Venge $P$, Lindahl B: $N$-terminal pro brain natriuretic peptide on admission for early risk stratification of patients with chest pain and no ST-segment elevation. Journal of the American College of Cardiology 2002, 40(3):437-45.

9. James SK, Lindback J, Tilly J, Siegbahn A, Venge P, Armstrong P, Califf R, Simoons ML, Wallentin L, Lindahl B: Troponin-T and N-terminal pro-B-type natriuretic peptide predict mortality benefit from coronary revascularization in acute coronary syndromes: a GUSTO-IV substudy. Journal of the American College of Cardiology 2006, 48(6):1146-54.

10. Bounameaux $H$, de Moerloose P, Perrier A, Reber G: Plasma measurement of D-dimer as diagnostic aid in suspected venous thromboembolism: an overview. Thrombosis and haemostasis 1994, 71(1):1-6.

11. Wannamethee SG, Lowe GD, Shaper AG, Rumley A, Lennon L, Whincup PH: Associations between cigarette smoking, pipe/cigar smoking, and smoking cessation, and haemostatic and inflammatory markers for cardiovascular disease. European heart journal 2005, 26(17):1765-73.

12. Freda BJ, Tang WH, Van Lente F, Peacock WF, Francis GS: Cardiac troponins in renal insufficiency: review and clinical implications. Journal of the American College of Cardiology 2002, 40(12):2065-71.

13. Aksoy N, Ozer O, Sari I, Sucu M, Aksoy M, Geyikli I: Contribution of renal function impairment to unexplained troponin $\mathrm{T}$ elevations in congestive heart failure. Renal failure 2009, 31(4):272-7.

14. QUALAB (the committee for Quality control in medical Laboratories in Switzerland). [http://www.qualab.ch].

15. de Torbal A, Boersma E, Kors JA, van Herpen G, Deckers JW, van der Kuip DAM, Stricker BH, Hofman A, Witteman JCM: Incidence of recognised and unrecognised myocardial infarction in men and women aged 55 and older: the Rotterdam Study. European heart journal 2006, 27:729-36.

16. Anderson JL, Adams CD, Antman EM, Bridges CR, Califf RM, Casey DE Jr, Chavey WE, Fesmire FM, Hochman JS, Levin TN, Lincoff AM, Peterson ED, Theroux P, Wenger NK, Wright RS, Smith SC Jr, Jacobs AK, Halperin JL, Hunt SA, Krumholz HM, Kushner FG, Lytle BW, Nishimura R, Ornato JP Page RL, Riegel B: ACC/AHA 2007 guidelines for the management of patients with unstable angina/non ST-elevation myocardial infarction: a report of the American College of Cardiology/American Heart Association Task Force on Practice Guidelines (Writing Committee to Revise the 2002 Guidelines for the Management of Patients With Unstable Angina/Non ST-Elevation Myocardial Infarction): developed in collaboration with the American College of Emergency Physicians, the Society for Cardiovascular Angiography and Interventions, and the Society of Thoracic Surgeons: endorsed by the American Association of Cardiovascular and Pulmonary Rehabilitation and the Society for Academic Emergency Medicine. Circulation 2007, 116(7):e148-304.

17. Lüscher MS, Ravkilde J, Thygesen K: Clinical application of two novel rapid bedside tests for the detection of cardiac troponin $\mathrm{T}$ and creatine kinase-MB mass/myoglobin in whole blood in acute myocardial infarction. Cardiology 1998, 89(3):222-8.

18. Fehr $T$, Knoflach A, Ammann P, Pei $P$, Binswanger $U$ : Differential use of cardiac troponin T versus I in hemodialysis patients. Clinical nephrology 2003, 59(1):35-9

19. de Giuli F, Khaw KT, Cowie MR, Sutton GC, Ferrari R, Poole-Wilson PA: Incidence and outcome of persons with a clinical diagnosis of heart failure in a general practice population of 696,884 in the United Kingdom. Eur J Heart Fail 2005, 7(3):295-302.

20. Remes J, Miettinen H, Reunanen A, Pyorala K: Validity of clinical diagnosis of heart failure in primary health care. European heart journal 1991, 12(3):315-21. 
21. Swedberg K, Cleland J, Dargie H, Drexler H, Follath F, Komajda M, Tavazzi L, Smiseth OA, Gavazzi A, Haverich A, Hoes A, Jaarsma T, Korewicki J, Levy S, Linde C, Lopez-Sendon JL, Nieminen MS, Pierard L, Remme WJ: Guidelines for the diagnosis and treatment of chronic heart failure: executive summary (update 2005): The Task Force for the Diagnosis and Treatment of Chronic Heart Failure of the European Society of Cardiology. European heart journal 2005, 26(11):1115-40.

22. Hobbs FD, Jones MI, Allan TF, Wilson S, Tobias R: European survey of primary care physician perceptions on heart failure diagnosis and management (Euro-HF). European heart journal 2000, 21(22):1877-87.

23. Cleland JG, Swedberg K, Follath F, Komajda M, Cohen-Solal A, Aguilar JC, Dietz R, Gavazzi A, Hobbs R, Korewicki J, Madeira HC, Moiseyev VS, Preda I, van Gilst WH, Widimsky J, Freemantle N, Eastaugh J, Mason J: The EuroHeart Failure survey programme- a survey on the quality of care among patients with heart failure in Europe. Part 1: patient characteristics and diagnosis. European heart journal 2003, 24(5):442-63.

24. Wright SP, Doughty RN, Pearl A, Gamble GD, Whalley GA, Walsh HJ, Gordon G, Bagg W, Oxenham H, Yandle T, Richards M, Sharpe N: Plasma amino-terminal pro-brain natriuretic peptide and accuracy of heartfailure diagnosis in primary care: a randomized, controlled trial. Journal of the American College of Cardiology 2003, 42(10):1793-800.

25. Zaphiriou A, Robb S, Murray-Thomas T, Mendez G, Fox K, McDonagh T, Hardman SM, Dargie HJ, Cowie MR: The diagnostic accuracy of plasma BNP and NTproBNP in patients referred from primary care with suspected heart failure: results of the UK natriuretic peptide study. Eur J Heart Fail 2005, 7(4):537-41.

26. Kearon C: Natural history of venous thromboembolism. Circulation 2003, 107(23 Suppl 1):122-30

27. Line BR: Pathophysiology and diagnosis of deep venous thrombosis. Seminars in nuclear medicine 2001, 31(2):90-101.

28. Schutgens RE, Haas FJ, Gerritsen WB, van der Horst F, Nieuwenhuis HK, Biesma DH: The usefulness of five D-dimer assays in the exclusion of deep venous thrombosis. J Thromb Haemost 2003, 1(5):976-81.

29. Leclercq MG, Lutisan JG, van Marwijk Kooy M, Kuipers BF, Oostdijk AH, van der Leur JJ, Buller HR: Ruling out clinically suspected pulmonary embolism by assessment of clinical probability and D-dimer levels: a management study. Thrombosis and haemostasis 2003, 89(1):97-103.

30. Schutgens RE, Ackermark P, Haas FJ, Nieuwenhuis HK, Peltenburg HG, Pijlman AH, Pruijm M, Oltmans R, Kelder JC, Biesma DH: Combination of a normal D-dimer concentration and a non-high pretest clinical probability score is a safe strategy to exclude deep venous thrombosis. Circulation 2003, 107(4):593-7.

31. Nielsen LS, Svanegaard J, Klitgaard NA, Egeblad H: N-terminal pro-brain natriuretic peptide for discriminating between cardiac and non-cardiac dyspnoea. Eur J Heart Fail 2004, 6(1):63-70.

32. Gustafsson F, Steensgaard-Hansen F, Badskjaer J, Poulsen AH, Corell P, Hildebrandt P: Diagnostic and prognostic performance of $\mathrm{N}$-terminal ProBNP in primary care patients with suspected heart failure. Journal of cardiac failure 2005, 11 (5 Suppl):S15-20.

33. Siebert U, Januzzi JL, Beinfeld MT, Cameron R, Gazelle GS: Costeffectiveness of using $\mathrm{N}$-terminal pro-brain natriuretic peptide to guide the diagnostic assessment and management of dyspneic patients in the emergency department. The American journal of cardiology 2006, 98(6):800-5.

\section{Pre-publication history}

The pre-publication history for this paper can be accessed here: http://www.biomedcentral.com/1471-2296/12/12/prepub

doi:10.1186/1471-2296-12-12

Cite this article as: Tomonaga et al:: Diagnostic accuracy of point-ofcare testing for acute coronary syndromes, heart failure and thromboembolic events in primary care: a cluster-randomised controlled trial. BMC Family Practice 2011 12:12.

\section{Submit your next manuscript to BioMed Central and take full advantage of:}

- Convenient online submission

- Thorough peer review

- No space constraints or color figure charges

- Immediate publication on acceptance

- Inclusion in PubMed, CAS, Scopus and Google Scholar

- Research which is freely available for redistribution

Submit your manuscript at www.biomedcentral.com/submit
Biomed Central 